\title{
Digital Life as a Topic of Business and Information Systems Engineering?
}

DOI 10.1007/s12599-014-0332-6

\author{
The Authors \\ Prof. Dr. Thomas Hess \\ Institute for Information Systems \\ and New Media \\ Ludwig-Maximilians-Universität \\ München (LMU) \\ 80539 München \\ Germany \\ thess@bwl.Imu.de
}

Prof. Dr. Christine Legner ( $₫)$

Faculty of Business and Economics (HEC)

University of Lausanne

1015 Lausanne

Switzerland

christine.legner@unil.ch

Prof. Dr. Werner Esswein

Prof. Dr. Wolfgang Maaß

Dr. Christian Matt

Prof. Dr. Hubert Österle

Dr. Hannes Schlieter

Peggy Richter, M.Sc.

Prof. Dr. Rüdiger Zarnekow

Published online: 2014-07-17

This article is also available in German in print and via http://www. wirtschaftsinformatik.de: Hess $\mathrm{T}$, Legner $C$, Esswein W, Maaß W, Matt $C$, Österle $H$, Schlieter $H$, Richter P, Zarnekow R (2014) Digital Life als Thema der Wirtschaftsinformatik? WIRTSCHAFTSINFORMATIK. doi: 10.1007/s11576-014-0422-6.

(C) Springer Fachmedien Wiesbaden 2014

\section{Introduction}

Business and information systems engineering (BISE) as a discipline connects management and economics on the one hand, and computer science on the other. Popular fields of research are for example, business applications, such as ERP or SCM systems, information management, business process redesign and en- terprise modeling, or more recently, IT based management concepts or business models. The anchor point, however, is the enterprise using IT. On this basis, BISE has successfully become established as an academic discipline, especially in German speaking areas.

This focus has been questioned more and more in recent years (Hess 2013). Initiated by a panel discussion at the Business and Information Systems Engineering Multi-Conference 2012 (MKWI) in Braunschweig, the first discussion paper in this series dealt with the question, whether BISE should also comprise ICT providers (Hess et al. 2012). In the discussion paper on hand we ask, whether BISE should include yet another application context: daily life. This time the initiative stems from a panel at the Business and Information Systems Engineering Multi-Conference 2014 (MKWI) in Paderborn.

Driver for this discussion is primarily the technological development. Information and communication technologies (ICT) were first used by businesses, especially in accounting. Meanwhile all areas of a business are involved with ICT. In addition, businesses are increasingly interconnected through the internet. However, the internet also enabled an efficient networking of individuals for the first time. Due to new, quite specific terminal devices with userfriendly interfaces, ICT has now penetrated private contexts, with applications that go far beyond simple email clients or e-banking.

In the meantime, a large spectrum of applications are changing and facilitating our private lives - from apps in the networked car, to heating controls, or mobile fitness and health assistants. These new applications open up the interdisciplinary field of "Digital Life", that is of high scientific and practical relevance. "Digital Life" denotes a private life that is strongly affected by the use of digital technologies.

As a research topic, Digital Life lies beyond the established research fields of BISE, which, in essence, deals with the development, usage, and effects of IT in enterprises and other organizations. Nevertheless, there are arguments in favor of including users and their real-world environment more than is currently done, as a topic of BISE:

(1) Although technologies are driving Digital Life, many technological innovations fail in practice due to user habits, organizational barriers, or the lack of viable business models. Recent examples include the low acceptance and diffusion of e-health solutions or the slow ingress of the connected car.

(2) BISE is engaged in the design of socio-technical systems. By focusing on an application context, methods and models in the field "User, Utility, and Use" (Brenner et al. 2014) already belong to core topics of BISE.

(3) German speaking BISE in particular, collated a comprehensive body of knowledge which could be of interest for the design of private user contexts: e.g., the use of models to analyze and conceptualize IT-enabled solutions, or a systematic development of IT artifacts in design oriented research.

We asked the following colleagues to provide their opinion on whether the topic Digital Life should take on a more important role in BISE and what consequences for BISE as a discipline this would have (in alphabetical order):

- Prof. Dr. Werner Esswein, Dr. rer. pol. Hannes Schlieter, and M.Sc. Peggy Richter, TU Dresden, Chair of Business and Information Systems Engineering, esp. Systems Development,

- Prof. Dr.-Ing. Wolfgang Maaß, Saarland University, Chair in Information and Service Systems,

- Dr. Christian Matt, LMU München, Institute for Information Systems and New Media,

- Prof. Dr. Hubert Österle, University of St. Gallen, Institute of Information Management,

- Prof. Dr. Rüdiger Zarnekow, TU Berlin, Chair for Information and Communication Management.

Werner Esswein, Hannes Schlieter, and Peggy Richter interpret Digital Life in health care as a metaphor for a electronic health record available for lifetime. This 
record adds a palette of additional information to traditional diagnostic and medical data, especially situation specific vital parameters and context data gathered by the latest sensor technologies. The concept of Digital Life breaks with the traditional institutional views of BISE, which focus on the information systems of medical service providers and their networks. By introducing a citizen-centered view, it lays the necessary groundwork for offering specific, individualized medical care as well as a proactive health care for citizens. Looking at ethical questions, the authors find the role of BISE to lie not only in researching for innovative and useful solutions but also in giving instructions for handling sensitive data and to indicate limitations.

Wolfgang Maaß connects Digital Life with what he calls "direal" worlds, that integrate digital services intrinsically, that is, not separable and in a natural manner, into a real-world everyday environment. His request is that if BISE is to include the topic Digital Life, it has to overcome its self-restriction to business contexts and accept digitally instrumented environments of everyday life as research objects. To accomplish this, extensions of the research methods (e.g., experimental approaches in design oriented research) and core objects of BISE (e.g., biological signals or electronic modules) are fundamental. Furthermore, research on Digital Life requires extensive multidisciplinary activities in mixed research teams with experts from, for instance, psychology, cognitive sciences, or engineering, and co-innovation in cooperation with start-ups, spin-offs, and SMEs.

Christian Matt characterizes Digital Life as a field of research, which focuses on all aspects of users' private lives. In his opinion, the different usage scenarios within the scope of privately used IT open up extensive research opportunities, because research has to date only covered the private user perspective selectively, or has not distinguished between professional and private use. The design of business models and value creation structures for end-user digital products and services offer additional research potential. As a discipline, BISE is positioned at the interface of management and economics on the one hand, and computer science on the other. It is therefore particularly suited to investigate Digital Life in its entirety and to participate in relevant design processes at an early stage.
Hubert Österle reports his experiences from the research project "Independent Living", that deals with digital consumer services for the rapidly growing share of elderly people in the population. Originally heavily focused on technologies, the project has in the meantime shifted towards studying concrete living spheres and aims to analyze, integrate, and further develop digital services for them. In view of the radical changes and of the economic potential of Digital Life, $\mathrm{Hu}$ bert Österle criticizes that BISE momentarily does not contribute enough to the development of innovative concepts and solutions and thus to seizing the market chances in the digital economy. In his view, BISE should assume a role similar to that in the beginning of enterprise IT and tackle more innovative research topics up to the development of a future consumer ERP.

Rüdiger Zarnekow analyzes computer games as an important part and technological driver of Digital Life, especially with younger users. Through their high innovation and market dynamics as well as their complete digitalization, computer games become an extremely interesting research subject within Digital Life. They offer opportunities to explore economic questions within individual gaming platforms and, on the level of the computer games industry, changes in value creation structures and business models. Moreover, "Game Analytics" and the fine-grained data on player behavior offer new opportunities to inquire into user acceptance or profit models. In addition, elements from computer games can be transferred to business information systems ("Gamification") to raise user motivation and thus the acceptance of the systems.

In conclusion, the authors look at the opening of BISE to the digitalization of everyday life as a necessity and chance for our discipline. They implore for an extension of BISE's traditional scope on enterprises or institutions towards more consideration of the users in their private living spheres. In some areas, e.g., health care and Independent Living, BISE researchers are already engaged in designing and evaluating innovative digital services and networked everyday environments of Digital Life. Their experiences emphasize that our discipline with its specific competencies in user acceptance studies and design oriented research has a good starting position. In order to cope with the paradigm change of
Digital Life and to shape the next phase of digitalization, however, BISE as a discipline has to extend the objects of research and the methodical spectrum, and to find new setups for multi-disciplinary research projects.

Prof. Dr. Thomas Hess Ludwig-Maximilians-Universität München

Prof. Dr. Christine Legner HEC, University of Lausanne

\section{Digital Life in Health Care}

Business and information systems engineering (BISE) research in the area of health care is dominated by an institutional view, focusing on the information systems of medical service providers and their business networks. However, even a rather traditionally oriented discipline like medicine is shaped by technological progress. On the one hand, highly specialized medical instruments for diagnoses and treatment are already available and will be further enhanced. On the other hand, the increasing divergence of medical services between metropolitan and rural areas fosters the adoption of telemedical solutions. All these trends, however, still serve the stereotype, that sees health care as medical care provisioning for a patient.

Digital Life, from the view point of health care, breaks with this stereotype and moves from an institution centered view to a citizen centered view. We interpret the concept Digital Life from this perspective as a metaphor for an electronic health record that is available for one whole life. It serves as a container for the storage of any data referring to health, like sports activities, traveling, environmental influences, or situation-specific vital parameters, which can be used to provide adequate care.

Furthermore, the term Digital Life includes the increasing integration of technological systems into the everyday life of the individual. This close linkage derives from sensor technologies generating context data (like wireless bio sensors, wearable ones, and so on), the possibility to interpret data semantically, and the permanent availability of information and communication. Current sensor technologies allow for a permanent monitoring of our environment and of our vital functions. Even information not recognizable to our senses can be 
permanently collected, monitored, and evaluated in a specific context. Apparently any information can be collected and interpreted, from the recording of motion and environment data to the measurement of detailed vital data, such as the pulse, breathing rate, body temperature, blood pressure, oxygen saturation in the blood, brain activity, and the tracking patterns of eye movement. Thus the concept of Digital Life goes beyond traditional medical and diagnostic data and includes a range of additional information, which allows targeted medical care. Individualized medical care thus is not a mere empty word any more, rather, the information basis exists to implement this concept.

Reversely, Digital Life includes the implementation of assistant functions, such as help, warning, or rescue systems. These assistant functions go beyond the first healthcare market and give the citizen a direct benefit from the acquired data. Both the digitalization of life in a lifelong electronic health record comprising a diversity of data and the strengthening of personal responsibility outside of hospital care contribute to protect citizens' health. Consequently, proactive prevention and health protection becomes equal in rank to the more reactive medical intervention.

Considering data protection, every responsible citizen should decide for him or herself whether he or she wants to make use of all technical possibilities. At the same time it must be emphasized that the right to privacy is facing the right to physical integrity. This points to the fact that a technical framework for the scenarios outlined must be created. Here BISE is requested to specify conditions and to develop design proposals.

Owing to the technological and social development, the concept of Digital Life, although its holistic application is still in its infancy, is already more than just a look into the future. Humans and information technology have been closely connected due to the continuous introduction of new and innovative technologies in our everyday lives. Our lifestyle is increasingly shaped by the everyday and ubiquitous availability and use of technical devices and the full connectivity through the internet. This development integrates both the objective and the digital world and makes the latter an inherent part of our lives.

Nevertheless, the described vision of Digital Life unavoidably evokes ethical questions, not only within health care. These questions must be taken into consideration by BISE when designing solutions. At this point, the discussion extends far beyond the metaphor of a "transparent" patient, as not only healthrelated data are collected, but conclusions can be drawn on the most intimate behavior, taken from the life-accompanying health record. Here, we have to consider trade-offs between what is technically feasible and the self-determination of citizens, as well as between the benefits and the risks of a digital life. Last but not least, social change has been made responsible for numerous psychological and psychosomatic diseases in society, partly caused by the rapid developments in the information and communication sector.

With the emerging technologies and their innovation potential, the pillars for realizing the vision of a Digital Life in health care are set. These must now be positioned on an adequate infrastructure and resilient operational concepts as foundation. At this point, we need to discuss to what extent it is a governmental or public responsibility to provide an appropriate infrastructure, control data protection and safeguard the ethical use of the data. BISE can establish itself here as an enabler, whose mission is to explore innovative and useful solutions and to help shape the frame and conditions for a sensitive approach. Similarly, BISE has the responsibility to identify ethical limitations and the duty to consider the social implications in all efforts to optimize and innovate.

The concept of Digital Life should be understood as a starting point for implementing the principles of individualized medicine and for strengthening the efforts to protecting citizens' health. Doubtlessly, it has the potential to revolutionize our healthcare system.

\section{Prof. Dr. Werner Esswein Dr. Hannes Schlieter Peggy Richter, M.Sc. TU Dresden}

\section{Direal Worlds - Intrinsic Imbedding of Digital Services in Real-World Everyday Environments}

After the millennium, business and information systems engineering (BISE) focused strongly on the digital world and research questions related to the reinvention of conducting business in the digital. Today, research questions are shifting more and more towards the use of information and communication technologies in physical, real-world everyday environments, that is outside of offices, production halls and warehouses. This trend is enforced by ubiquitous mobile telephony and more widely distributed technologies for sensors, actuators/robots and 3D printing. Ubiquitous Computing, Ambient Intelligence, Experiential Computing, Internet of Things, Industry 4.0 and Smart Service World are general terms on the side of applied research dealing with the embedding IT in real-world environments. The design of such hybrid (digital-physical) information systems in professional and everyday environments represents a new challenge, which BISE should particularly address.

Digital Life emerges when digital services are seamlessly integrated into realworld environments, i.e., not separable and in a natural way. While designing such environments it must be determined, to what avail and with what benefits our lives are already pervaded by such services (analytical problem) or can be pervaded (design question). In addition to the technical and economic feasibility social and legal issues arise, which to date, only appeared in science fiction novels. To give examples: It is now technically possible to stick sensors onto the outside of the heart to collect quasi-objective data of the cardiovascular system in real time, to display them on smartphone apps, forward them to the doctor, and have them investigated for abnormalities in a digital biobank, using data science methods. These peculiarities could potentially be passed on to insurance companies for the purpose of dynamic adaptation of policies, with subsequent adaption of the career planning by the employer. Furthermore, the airline could be informed on the next trip, so that the next longdistance flight or the entry into the destination country will be refused. Such situations raise various questions which our society has to answer and for which BISE should develop a clear position.

The penetration of real environments with cross-linked, intelligent productservice integrations is already quite advanced in the military field. Thus it can be assumed that penetration will not stop at further fields of professional and everyday situations. These intelligently networked real-world environments offer an 
enormous potential for optimization and development. It should thus be examined whether, for example, health care can be enhanced by seamlessly embedded intelligent service networks, and what effects this will have on the funding of the entire health care system. Evidence can be given by "Quantified Self" applications, such as Fitbit or Withings. The same applies to companies which, inspired by global competition, rethink their existing production environments, as is currently discussed as fourth industrial revolution or Industry 4.0.

At large, digital and real-worlds combine to become a "direal world" in which both can no longer be separated. In the way as one cannot run an operating room without invasive methods and intrinsically related digital services or a car cannot be driven without digital services, kitchens will be created which help us fry a steak to perfection and bedrooms that provide us with a sleeping pattern analysis in the morning and give suggestions for improvement.

BISE has been defined up until now as a discipline that investigates development and application of information and communication technologies in enterprises. In order to open up to Digital Life, BISE has to move out of its self-limitation to business contexts and embrace environments of everyday life.

Via the following exemplary discussion points the discipline of BISE could approach the topic Digital Life:

- Extension of the research perspective to embrace everyday environments and related working environments.

- Inclusion of user or customer -centric views, especially concerning behavior in everyday environments.

- Application of design oriented approaches, especially using experimentally oriented research (example: RoboCup).

- Overcoming the traditional boundaries between the disciplines: promotion of inter and trans-disciplinary research.

- Extension of the core objects of BISE research to cover, for instance, biological signals (e.g., skin conductance, DNA sequences), private spheres, memory skills, electronic components, production machinery.

- Opposing methodical reductions and encouraging a broader set of research methods by adoption and adaption of suitable methods from computer science, business administration, psychology, cognition sciences, healthcare, engineering, electrical engineering, mathematics, etc.

- Active support of the innovative research potential in the field of Digital Life, especially by promoting start-ups, spin-offs, and cooperation with small and medium sized businesses.

\section{Prof. Dr.-Ing. Wolfgang Maaß Saarland University}

\section{The User as a Central Element of BISE - also Beyond the Firm}

\subsection{Digital Life as a Field of Research}

Peoples' private lives are increasingly affected by digital technologies. This development is referred to as "Digital Life." A main driver of the digitization of our lives is the increasing distribution of new digital (partially mobile) products and services, such as smartphones and tablets, but also internet-enabled TVs and various intelligent household devices. In the digital age, an increasing number of technologies can be linked to each other and operated remotely. The digitization has also enabled the connection of technologies with different original purposes (e.g., solar energy panels that control when a washing machine operates). Digital Life's application context is not limited to users' homes, but extends to their private lives as a whole, for example, the use of digital technologies when driving their cars, or when engaging in outdoor activities. For many (mostly young, but also older) users, digital technologies are no longer merely part of their work activities, but are an every-day component of their private lives.

Business and Information Systems Engineering (BISE) has traditionally, and with considerable success, dealt with the development, use, and effects of ICT in enterprises. Here, users are considered an integral part of their working environment, or are even used as a proxy for an enterprise's decision making. Because users act as part of their working environment, they act at least partly heteronomously. Conversely, in their private lives, users make their own decisions. Here, they either act completely in their own interest, or as a part of their private social environment (e.g., family or friends). In this private context, users are usually directly financially responsible for the consequences of their adoption and usage decisions. Furthermore, these decisions often concern digital technologies, which are distinct from those technologies they use professionally. Altogether, this suggests that the professional usage context is substantially different from the private usage context and that it should therefore receive dedicated attention.

\subsection{Relevance for Research and Practice}

To date, research has covered the private usage context only selectively (e.g., research on privacy or mobile technologies) and has not always distinguished explicitly between professional and private usage. Since the differences between these two are fundamental, it is doubtful that traditional models and theories developed in a working environment can be applied unchanged to the private usage context. Far too often, research adopts theories from the institutional context without verifying these theories' applicability in the private context. Venkatesh et al. (2012) criticize this practice and specifically adopt their "Unified Theory of Acceptance and Use of Technology" (UTAUT) to the consumer context. Likewise, the suitability of theories and models frequently used in BISE should be carefully verified before applying them in the private usage context. Amendments should be made, or entirely new concepts developed if required.

In this regard, the private context's different usage and effect scenarios offer a diverse potential for further research. For example, the evolvement of software ecosystems has led to new and more complex decision making situations for users. Focusing on the user as the main subject of Digital Life allows suppliers to profit from the novel insights into users' needs and expectations regarding the design and development of digital products and services. While proprietary standards and high product prices have hindered the greater diffusion of certain digital technologies in recent years (e.g., in the context of home automation), smartphones and other mobile devices now function as a central, cost-effective platform that allows various kinds of technologies to be connected and controlled. Nevertheless, many providers of new end-user technologies continue to face key challenges. For instance, users often do not adopt new digital technologies because they are unaware of their benefits, or do not value their capabilities. It is therefore essential 
for suppliers to obtain new insights into the determinants of acceptance and the continuous use of technologies. Developing suitable revenue and business models will ensure that suppliers enjoy continuing success. In this context, new questions (e.g., regarding the management of ecosystems) have to be answered, but also well-established issues (such as adoption decisions) require dedicated attention in this new context. As a research field, Digital Life could make a decisive contribution to these theoretical and practical issues.

\subsection{How Should BISE Deal with Digital Life?}

As a discipline, BISE is particularly suited to deal holistically with Digital Life. BISE is not only positioned at the interface between business administration and computer science, but has established extensive expertise in the area of user acceptance of technologies. BISE can now benefit from this knowledge in order to find answers to the issues emerging from the increasing digitization of our private lives. In this context, BISE has an advantage over other disciplines: Computer science research hardly deals with profound economic concepts and considerations, while marketing research may not have the necessary technology competency to understand the underlying technological phenomena. BISE should use its skills to actively participate in the evolvement of Digital Life at an early stage. A reluctance to embrace this issue could prove to be a strategic mistake, as professional and private usage scenarios tend to converge strongly in some areas (e.g., "bring your own device," which refers to the integration of private information and communication technologies into enterprises).

Possible Digital Life topics and projects are manifold and include the development, use, and effects of new digital technologies. Currently, there are also interesting research questions in end users' technology management. In addition, various areas that have profited from a major increase in research intensity during the past few years (e.g., Health-IS and E-Energy) still offer major research challenges that refer to the private usage context.

However, explanatory approaches alone do not suffice in any of these areas. High priority should therefore also be given to design-oriented approaches by, for example, developing prototypes.
Appropriately applied, the combination of design-oriented and empirical research could provide additional value both for research and practice. BISE has in recent years built an extensive competency in both methodological fields and can thus play an important role in the development of Digital Life.

\section{Dr. Christian Matt LMU München}

\section{Independent Living - Research Questions for BISE}

\subsection{Spheres of Life}

In 2006, the Institute of Information Management at the University of St. Gallen started its research project "Independent Living". Its goal was to give elderly people a chance to stay in their own homes independently for as long as possible by using information technology. The project aimed at digital consumer services for the fastest growing segment of the population, people that have concluded their professional careers. Thus it addresses an important part of Digital Life.

After an initial technological euphoria with the focus on tele medicine, intelligent household appliances, mobile video communication and so on, the project Independent Living shifted towards successful partial solutions, their integration and development, based on concrete experiences with these technologies and actual user needs.

Based on these experiences we first identified ten human spheres of life which were inspired by categories of appstores (e.g., Apple) and app market researchers (e.g., distimo). Secondly, we collected digital services (mobile apps, websites, and intelligent appliances) and mapped them to the spheres. This app map, including around 500 services, does not claim to be complete but is supposed to provide examples for the functionality available on the market today. It is available via http://IL.iwi.unisg.ch/AppMap.

- The living sphere entertainment stands for games, music, video, social interaction, literature, and information with innumerous facets.

- Communication comprises the technical tools used for communication in work and private life, i.e., phone instant messaging, email, social networks, and telepresence.
- Shopping stands for product and service search, product information, the purchasing process itself, the ordering of services, payment methods, coupons, manuals and recommendations.

- Home ranges from the tenants' portal to order the repair service, the lawn robot and the alarm system up until local renting offers.

- Sport, healthcare, monitoring vital signs, personal documentation, therapy manuals, emergency services, but also philosophy, religion and life coaching form the area of health.

- Mobility is another quite important sphere of life that includes digital services such as navigation, traffic control, self-driving, taxi, travel booking, accommodation sharing, and public transport.

- Productivity embraces all services that relieve people of administrative tasks in their private and professional lives. Time management, authentication, contact management, documentation, and data backups are examples.

- Under the area jobs we understand services such as job search, remote office work, and crowd sourcing or volunteering. A separate area, not detailed in the app map, forms the working place, i.e., all operational functions that a person uses as an employee of a company, i.e. the classic topics of business and information systems engineering (BISE) and business administration.

- Finance relates to managing personal finances, especially the cooperation with banks, insurance companies and other financial service providers.

- Life management finally is the apex of consumer services. According to statements made by technology companies like Google, Apple, or Samsung they intend to help people manage their lives. This is at present more a vision than a realistic offer, but it is apparent that these companies integrate more and more of the services described above. They thus aim to relieve consumers from the shortcomings of non-integrated solutions, such as multiple authentifications, different user guides, or the software updates of numerous applications.

\subsection{Economic Potential}

Brynjolfsson and McAfee (2014) sketch the vision of a digital economy governed by laws that are extremely dif- 
ferent from the ones we know in the traditional industrial society. If we take the market capitalization of companies as an indication of their value and their potential for the future, the example of just a few new and classic large enterprises illustrate the profound changes described by the authors (market capitalization in billion EUR on 2014-04-14): Apple 338, Google 242, Microsoft 236, Nestle 179, Samsung 156, Facebook 109, Volkswagen 89, Daimler 71, Deutsche Post 32, Tesla 18, Deutsche Lufthansa 9.

Of course, the market capitalization of technology companies is very volatile, and other indicators such as the number of employees (including subcontractors) determine their economic importance. If one analyzes the publications of BISE, particularly in so called top journals or at conferences, our discipline contributes little to seize opportunities in the digital economy. Rather, it is to be feared that the mainstream and its representatives stop the young generation of researchers, teachers, and practitioners from engaging themselves in future issues outright.

\subsection{Research Questions}

In the early days of the digital economy, BISE contributed significantly to the conception and the development of business software, especially integrated ERP systems. The opportunism in seizing publication chances in the above mentioned top journals has led, in many cases, to favoring behavioristic studies which evaluate already existing solutions, instead of supporting the next generation in creating something new along design orientation.

As an argument against research in the consumer services mentioned above it is sometimes put forward that consumers are not enterprises and therefore not the subject of our discipline. It is also argued that the specialized knowledge of medicine, media studies, or other disciplines is necessary for their investigation. But who if not BISE could deal with digital business models, service marketplaces, the processes for appointment management, or online stores and almost all other issues raised in the app map? A few examples of exciting research questions are:

- Why is Yelp successful? What are the relevant revenue streams for such portals?
- Which services are available to match offers and applicants for micro jobs?

- Which qualities make a service attractive for consumers?

- Which functions need a service for interpersonal time management?

- What does democratic identity management look like?

- What does a consumer ERP (a digital consumer assistant) look like? What functionality does a person need for his or her private administration? What information and documents must he or she be able to manage? How can he or she pass on these data independently and selectively to business partners case by case? How can the consumer assistant relieve people from the management of IT?

In these research questions, we find both behavioral science and designoriented research topics with a high utility potential. Various, mainly technology-related research centers, that deal with the design of prototypes and pilots for consumers have turned to consumer services in recent years. BISE has the chance to help shape the digital consumer world comparable to the way it shaped the business world 50 years ago.

Prof. Dr. Hubert Österle University of St. Gallen

\section{Computer Games as Part of Digital Life}

Digital Life comprises the increasing penetration of private spheres of life with digital technologies. Although a wider discussion of this phenomenon in business and information systems engineering (BISE) has only started recently, certain aspects of Digital Life, such as computer games, have been studied for some time. Computer and video gaming has long moved away from being a niche industry. The global market size of the industry is currently estimated at USD 60 to 70 billion, about $5 \%$ of which are turned over in Germany. Constant annual growth rates of $5-7 \%$ underline this development. Global players such as Activision Blizzard (annual sales USD 4.6 billion), or the Chinese company Tencent (annual sales USD 5.3 billion) show that the market has reached a stage of maturity. In Germany, according to the German Trade Association of Interactive Entertainment Software, there are now more than 10,000 people employed within the computer games industry.

Among the various topics of Digital Life, computer games provide an interesting field of research for BISE. Development cycles are highly innovative and dynamic. Hardware, software, and network technologies play a central role; often computer games are the technological driving force for the entire IT industry. The value chains and processes in the industry are largely digitalized. Also the huge number of computer players provide an excellent basis for quantitative and qualitative studies. Many research questions also require an interdisciplinary approach and combine technological, economic, sociological, and psychological challenges.

Digital technologies form the core elements of Digital Life. In the gaming industry these are mainly the technical gaming platforms and the games made available through them. They constitute an example of high innovation and market dynamics. A multitude of new gaming platforms have been developed over the last years in addition to the classic console and PC platforms, e.g., hand helds, tablets, smartphones, or Internet/Online. Game genres have become much more diverse and now include e.g., action and shooter games, sports, adventure, and strategy games as well as role playing games, casual/social games, and serious games. Device-independent platform architectures and consequently a variety of new application scenarios are made possible by new technologies, such as cloud gaming or streaming platforms. Here, the actual computer games are run on powerful servers of a cloud service provider and only the generated game interfaces are transmitted as video streams to the end-user devices over the Internet. Respectively, players input, such as keyboard or mouse input, are sent back to the game server from the end-user device. In this way it becomes technically possible to play sophisticated, resourceintensive games on almost all devices, and in particular on tablets or smartphones.

Both within specific gaming platforms and in the computer games industry as a whole, numerous economic questions arise which are interesting for BISE. The classic value creation structures of the industry (game designer, publisher, and distributor) undergo dramatic changes. Designers get the chance to distribute 
their games directly to the customers via the app stores of big producers like Apple, Google, or Microsoft. Digital distribution of games through platforms like Steam, gain in importance rapidly and play a significant role in the market today. Revenue models change in the same dynamic way. Besides the classic sale of games for a fixed price charged as upfront fee, a multitude of new revenue models are being tested. These range from monthly usage fees, to "freemium" models and, revenue models funded by advertisements and in-game purchases. The sale of virtual goods in the computer games industry alone has already grown to revenues of approximately USD 15 billion in 2012, which is roughly the total volume of the global music industry. Still, it is uncertain which revenue models will prove viable in the long run and how they should be designed in detail, despite this early success. For example, there is only very limited knowledge regarding the use of "Freemium" models and the best moment to motivate or force a player to make the first payment.

Starting points for BISE can also be found in the rapidly developing research field of game analytics. Many game designers and platform operators now have very comprehensive and finegrained data on in-game player behavior. These data, for example, on purchases and payment dates, frequency of use, or the playing duration, are the basis for sta- tistical analyses. These in turn allow for gaining detailed insights into the acceptance of certain game items or revenue models, with the ultimate goal of better understanding the players and their gaming behavior.

The concept of "gamification", discussed more often lately, describes a direct link between computer games and the classic focus of BISE on professional information systems. By incorporating game elements into business information systems, the user motivation and thus the acceptance of the systems can be increased. Gamification focuses specifically on intrinsic motivation factors, such as social recognition and reputation, interaction with colleagues, or the disclosure of experiences of success. With many years of experience in the field of business information systems, BISE inevitably takes on a central role in the successful design and implementation of gamification concepts.

One may assume that computer games will be a technological driving force within Digital Life in the future as well. Virtual Reality, as one of the alleged next technological megatrends, is close to a breakthrough, as various VR glasses designed for the consumer market demonstrate (e.g., Oculus Rift or Sony Project Morpheus). Virtual Reality technologies will first be tested in a new generation of computer games before they spread to other areas of Digital Life. Therefore, it will be worthwhile to study intensively the future developments in the field of computer games.

Prof. Dr. Rüdiger Zarnekow TU Berlin

\section{References}

\section{to: Section 1}

Brenner W, Karagiannis D, Kolbe L, Krüger $J$, Leifer L, Lamberti H-J, Leimeister JM, Österle $H$, Petrie $C$, Plattner $H$, Schwabe G, Uebernickel F, Winter R, Zarnekow R (2014) User, use \& utility research: the digital user as new design perspective in business and information systems engineering. Bus Inf Syst Eng 6(1):55-61. doi:10.1007/s12599-013-0302-4

Hess T (2013) Wirtschaftsinformatik als akademisches Fach: Fokus Anwenderunternehmen oder doch mehr? In: Arbeitsberichte des Instituts für Wirtschaftsinformatik und Neue Medien der LMU München, Nr. 1/2013

Hess T, Loos P, Buxmann P, Erek K, Frank U, Gallmann J, Gersch M, Zarnekow R, Zencke P (2012) ICT providers: a relevant topic for business and information systems engineering? Bus Inf Syst Eng 4(6):367-373. doi:10.1007/s12599-012-0235-3

\section{to: Section 4}

Venkatesh V, Thong JYL, Xin X (2012) Consumer acceptance and use of information technology: extending the unified theory of acceptance and use of technology. MIS Q 36(1):157-178

\section{to: Section 5}

Brynjolfsson E, McAfee A (2014) Second machine age: work, progress, and prosperity in a time of brilliant technologies. Norton, New York 